\title{
Nerve Entrapment Syndromes in Competitive Triathletes
}

\author{
Damián Palafox ${ }^{1}$ \\ 1Plastic and Reconstructive Surgery Department, Hospital Ángeles \\ Puebla, Puebla, Mexico
}

Indian J Plast Surg:2020;53:454-454

In recent years, the number of female and male athletes participating in triathlon events has risen worldwide. It is quite a fascinating sport that encompasses three sport disciplines that demand both mental toughness and physical aptitude. Nevertheless, high-volume training without proper rest or without guidance make athletes prone to nerve entrapment symptoms, which render particular interest for healthcare professionals involved in peripheral nerve surgery.

Supraorbital neuralgia has been described during swimming. ${ }^{1}$ Supraorbital notch pain is related to the use of certain goggles that could lead to direct compression on the territory of the supraorbital and supratrochlear nerves. Although this condition on swimmers is often temporary and does not require further study or treatment (only patient counseling), it is important to perform a differential diagnosis with other entities such as chronic migraine or supraorbital rim syndrome, clinical conditions that do require surgical treatment. 2,3

In contrast to swimming (where nerve compression is self-limited and relieved after the cessation of the activity), cycling and running are related to nerve entrapment that could cause significant disability. Electrophysiological evaluation studies have demonstrated that long-distance cycling could elicit changes in the deep branch of the ulnar nerve. ${ }^{4}$ Prolonged cycling involves sustained compression on the volar aspect of the hand of the athlete, who typically changes positions according to the road characteristics. Although aerobars allow for a more aerodynamic cycling position and avoid pressure on the ulnar nerve territory, some triathlon events have regulations where this sort of equipment is not permitted. If a regular handlebar is to be used, hyperextension of the upper extremity and a novice position of the wrist occurs (particularly at the horn handle). Symptoms typically involve numbness and paresthesias, such as those encountered on Guyon's canal syndrome. Patients may experience sensory and motor
Address for correspondence Damián Palafox, Plastic and Reconstructive Surgery Department, Hospital Ángeles Puebla, Kepler 2143, Puebla 72190, Mexico (e-mail: elysiamplastica@gmail.com).

symptoms. Although the ulnar nerve is the main structure involved, a study demonstrated symptomatic worsening of carpal tunnel syndrome in some athletes and even onset of the syndrome after a long cycling tour. ${ }^{4}$

Finally, one must consider that the athlete is beginning to run after T2 (the second transition in a triathlon event), that is, after swimming and cycling. Training plans for both recreational and advanced levels include brick sessions, where a full cycling workout is followed immediately by a run workout. Overload is well-recognized to be directly related to injuries in sport science. Most nerve entrapment symptoms during running occur in the lower limb, especially in the hip region. As experts in the field have noted, the main affected nerves are the sciatic, pudendal, femoral, obturator, and the lateral femoral cutaneous. ${ }^{5}$ In case surgery is needed, complete nerve decompression and/or neurolysis is strongly advised.

\section{Conflicts of Interest}

None declared.

\section{References}

1 Pestronk A, Pestronk S. Goggle migraine. N Engl J Med 1983;308(4):226-227

2 Hagan RR, Fallucco MA, Janis JE. Supraorbital rim syndrome: definition, surgical treatment, and outcomes for frontal headache. Plast Reconstr Surg Glob Open 2016;4(7):e795

3 Ducic I, Larson EE. Posttraumatic headache: surgical management of supraorbital neuralgia. Plast Reconstr Surg 2008; 121(6):1943-1948

4 Akuthota V, Plastaras C, Lindberg K, Tobey J, Press J, Garvan C. The effect of long-distance bicycling on ulnar and median nerves: an electrophysiologic evaluation of cyclist palsy. Am J Sports Med 2005;33(8):1224-1230

5 Martin R, Martin HD, Kivlan BR. Nerve entrapment in the hip region: current concepts review. Int J Sports Phys Ther 2017;12(7):1163-1173 published online

August 20, 2020
Dol https://doi.org/

10.1055/s-0040-1715190

ISSN 0970-0358.
(C)2020. Association of Plastic Surgeons of India.

This is an open access article published by Thieme under the terms of the Creative Commons Attribution-NonDerivative-NonCommercial-License, permitting copying and reproduction so long as the original work is given appropriate credit. Contents may not be used for commercial purposes, or adapted, remixed, transformed or built upon. (https://creativecommons.org/licenses/by-nc-nd/4.0/).

Thieme Medical and Scientific Publishers Pvt. Ltd. A-12, 2nd Floor, Sector 2, Noida-201301 UP, India 